\title{
エタノールアミンオレエート注の品質試験*1
}

西川三喜男, 鈴木一市, 森田久代, 川影逸郎, 藤井喜一郎

捠松医科大学医学部附属病院薬剤部*2

\section{Quality Test of Ethanolamine Oleate Injection*1}

\author{
MIKIo NishiKaWA, KaZUichi SUZUKI, HISAYo MoRITA, ItSURo KaWAKage, \\ KIICHIRO FUJII \\ Hospital Pharmacy, Hamamatsu University School of Medicine*2
}

(Received July 9, 1985)

\begin{abstract}
Quality tests were made on two kinds of oleic acids as raw materials (OA), JIS extra pure reagent (OA-JIS) and guaranteed reagent with content of about $99 \%$ (OA-GR), which were used for the material of ethanolamine oleate injection (EO- $i$ ). Furthermore, the effect of the difference of $\mathrm{OA}$ on the quality of EO- $i$ was studied.

The content of peroxide in OA-JIS was higher when it was stored at room temperature than in a cold place. Therefore, it is necessary to store OA-JIS in consideration not only of light and air but of temperature.

The $\mathrm{pH}$ of EO- $i$ with OA-GR was same as that with OA-JIS, while the viscosity of EO- $i$ with OA-GR was higher. EO- $i$ with OA-GR remained colorless before and after sterilization, whereas in the case of OA-JIS, the pale yellow color became more intense by sterilization. Light and temperature had no effect on the stability of EO- $i$, e.g., production of peroxide, the content of oleic acid and $\mathrm{pH}$.

Although the further comparative study on effectiveness and safety of OA-GR and OA-JIS as the sclerosing agent for esophageal varix is necessary, it is thought, from the above results, that the use of OA-GR is desirable in pharmaceutical aspect.
\end{abstract}

Keywords — ethanolamine oleate injection; quality test ; oleic acid; content; peroxide; stability; esophageal varix; GC method

\section{緒}

Ethanolamine Oleate Injection (以下 EO- $i$ と略) は英国薬局方 (以下 BPと略) に収載されており,1) 1950 年代にはすでに静脈瘤の硬化剂として使用されている2 長い歴史をるつ薬剤である.1970年代からは内視鏡の進 歩に伴い食道静脈瘤の硬化剂として急速に用いられるよ らになった. ${ }^{3,4)}$ その品質や安定性に関する報告は少ない が, 武田ら 5$)$ は, 冷暗所保存した場合窒素置換の有無に 関係なく $\mathrm{pH}$ ，含量とも 8 週間変化はみられなかったと 報告している．しかし製剤原料の品質に関する報告はな

*1 日本薬学会第 105 年会（金沢, 1985年 4 月）で発 表.

*2 浜松市半田町 $3600 ; 3600$, Handa-cho, Hamamatsu-shi, 431-31 Japan
く, 特にオンイン酸原料（以下 OA と略）は近年高純度 のものが得られることから, その原料を選択する際には 品質の検討が重要となる. そこで今回 2 種類の OA, す なわち JIS 一級品と含量約 $99 \%$ の高純度品の品質を比較 検討し, さらに OA の違いが EO- $i$ の品質にどのような 影響を及ぼすか検討した. 安定性に関しては含量以外に 脂肪酸の自動酸化の初期生成物質である過酸化物（以下 PO と略）を中心に評価した.

\section{実 験 の 部}

\section{1. 試 薬}

ガスクロマトグラフ法に用いる脂肪酸の標準品として ミリスチン酸, ステアリン酸, パルミチン酸(以上シグ マ社製, 含量約 $99 \%$ ), オレイン酸, リノール酸 (以上, 和光純薬製生化学用, 含量約 $99 \%$ ）を使用した. その他 
Table 1. Oleic Acid (OA) Used for Quality Test

\begin{tabular}{cccc}
\hline Sample & Grade & Lot. No. & Container*2 $^{*}$ \\
\hline A & JIS extra pure & PEJ 4049 & $500 \mathrm{~m} \ell$ Bottle \\
A $^{\prime * 1}$ & JIS extra pure & LTJ 2338 & $500 \mathrm{~m} \ell$ Bottle \\
B & JIS extra pure & 3434 & $500 \mathrm{~m} \ell$ Bottle \\
C & JIS extra pure & M3T 6875 & $500 \mathrm{~m} \ell$ Bottle \\
D & Guaranteed reagent & TSQ 7549 & 10 AL Ampul $^{* 3}$ \\
\hline
\end{tabular}

*1 Stored for 20 months after opening the bottle *2 Light resistant

*3 Covered with black paper and stored at $2 \sim 10^{\circ}$ $\mathrm{C}$

Table 2. Composition of Ethanolamine Oleate Injection (EO- $i$ )

\begin{tabular}{lr}
\hline \hline Ethanolamine & $0.91 \mathrm{~g}$ \\
Oleic acid & $4.23 \mathrm{~g}$ \\
Benzyl alcohol & $2 \mathrm{~m} \ell$ \\
Water for injection & to $100 \mathrm{~m} \ell$ \\
\hline
\end{tabular}

の試薬は特級を用いた。

\section{2. 原料および試料の調製}

1) オレイン酸原料: JIS 一級品は和光純薬 $\left(\mathrm{A}, \mathrm{A}^{\prime}\right)$, 片山化学 (B), 半井化学 (C) の 3 社 4 品目を用い, 高 純度品は和光純薬製生化学用 (D) を用いた。ロット番 号, 容器, 容量を Table 1 飞示す.

2）EO- $i$ の調製：BP 従い調製した. エタノールア ミンは試薬一級を、ベンジルアルコールは試薬特級を用 いた. 処方を Table 2 に示す. また Evans 社 (Green" ford, Middlesex Lot No. B0644FA) の製品を品質評価 の対照に用いた。

\section{3. 脂助酸の同定および定量}

1）オレイン酸の定量

ガスクロマトグラフ法で測定した。 OA 中の含量はそ の $0.25 \%$ クロロホルム溶液を測定試料とし, $\mathrm{EO}-i$ 中の 含量は, EO- $i \mathrm{ml}$ に希塩酸 $1 \mathrm{ml}$ を加光混和後ク口ロ ホルム $20 \mathrm{ml}$ で抽出し測定試料とした. 次の条件で測定 し, 定量は絶対検量線法で行った. 装置 : 日立 163 型, カラム: DEGS $5 \%+\mathrm{H}_{3} \mathrm{PO}_{4} 1 \%$, Uniport HP $60 / 80$ $1.5 \mathrm{~m} \times 3 \mathrm{~mm}$ i.d. Glass, カラム温度 : $200^{\circ} \mathrm{C}$, 試料導入 部温度 : $250^{\circ} \mathrm{C}$, 窒素流量 : $50 \mathrm{ml} / \mathrm{min}$, 注入量 : $2 \mu 1$

2）原料中の脂肪酸の同定および定量

$\mathrm{OA}$ の $2.5 \%$ クロロホルム溶液を測定試料とし, ガス
クロマトグラフ法により同定および含量測定を行った. スタンダードには各脂肪酸の標準品の $0.125 \%$ クロロホ ルム溶液を用いた，測定条件はカラム温度を $180^{\circ} \mathrm{Cにし}$ た以外は前述と同じである。

\section{4. 過酸化物の含有量の測定}

OA はその約 $1 \mathrm{~g}$ を精密に量り衛生試験法に準拠し測 定した。また EO- $i$ はその $50 \mathrm{ml}$ を正確に量り希塩酸 $4 \mathrm{ml}$ を加えた後, クロロホルム $5 \mathrm{ml}$ で 3 回抽出し, 全 量 $20 \mathrm{ml}$ とした. その $10 \mathrm{ml}$ を正確に量り酢酸 $15 \mathrm{ml}$ を 加え混和し, 以下衛生試験法に準拠し測定した。

\section{5. ヨウ素価測定}

OA 約 $0.3 \mathrm{~g}$ を精密に量り, 第十改正日本薬局方の油 脂試験法に準拠し測定した。

\section{6. $\mathrm{pH}$ 測定}

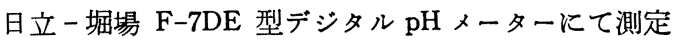
した。

\section{7. 粘度測定}

東京計器 $\mathrm{BL}$ 型粘度計にて測定した.ローターは BL アダプターを用い, $60 \mathrm{rpm}, 37^{\circ} \mathrm{C}$ で行った。

\section{結果および考察}

\section{1. オレイン酸原料}

1）品質比較試験

OA の品質比較結果を Table 3 に示す. JIS 一級品 (A, A', B，C）では外観, ヨウ素価とも JIS で規定さ れており,6) 試験結果はその範囲内であった. しかし JIS には規定されていないがオレイン酸の含量は65～70\%と 低かった.すなわち，オレイン酸以外に30\%以上の混在 物が含まれており，注射剤の原料として使用するにはこ の混在物を明らかにする必要があり, 主に混在している と思われる脂肪酸の同定, 含量測定を行った. Fig. 1(a) にJIS一級品Aのクロマトグラムと各脂肪酸の保持時間 および定量値を示し, Fig. 1(b) に高純度品Dのクロマ トグラムを示した．Dのピークからほぼオレイン酸の単 一成分と考えられるが，Aでは多数のピークが見られ た。

また，他の JIS 一級品も A と同様のクロマトグラムを 示したことから, JIS 一級品中の成分はどのメーカーの 原料ですほぼ同一であると考えられる.これらのピーク 中, 同定および含量測定を行ったのはミリスチン酸, パ ルミチン酸, ステアリン酸, オレイン酸, リノール酸 でこれらの脂肪酸の含量を合計すると約 $80 \%$ であっ た.この中には飽和脂肪酸が約 $10 \%$ 含まれている. 食道 静脈瘤の硬化剂としての飽和脂肪酸は不飽和脂肪酸より 他臓器の栓塞, アレルギー等の副作用の発現率が高く毒 
(a)

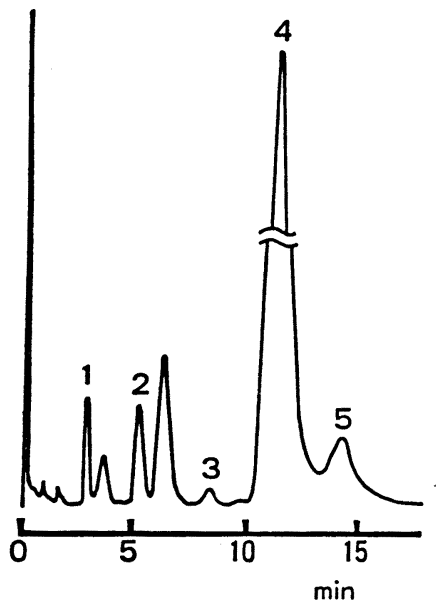

(b)

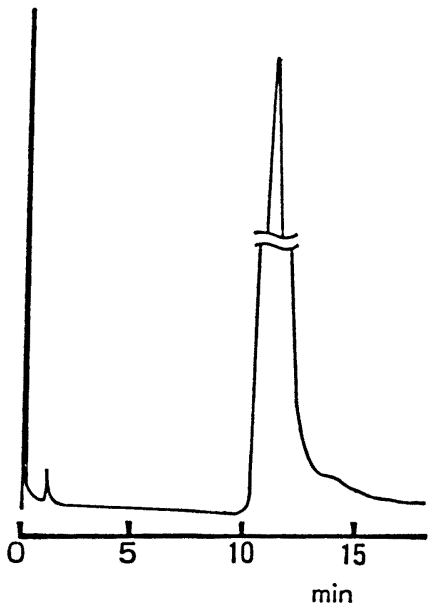

(c)

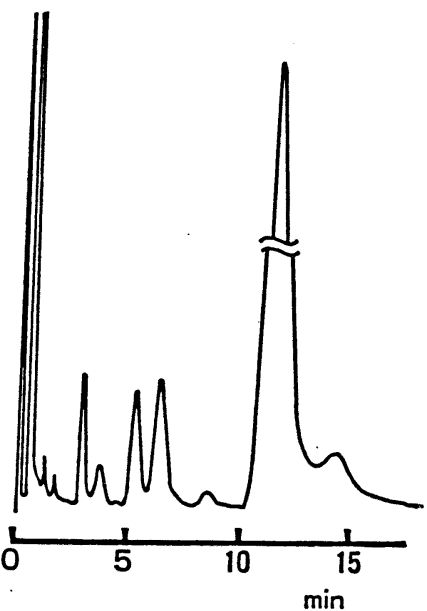

Fig. 1. Gas Chromatogram of (a) Sample A and (b) Sample D and (c) OA in EO- $i$ of Evans

Retention time ( $\mathrm{min}$ )
3.0
5.3
8.3
11.3
14.1

2.5
5.6
1.5
69.9
1.9
2.5
1.5
69.9
1.9

Content $(\mathrm{w} / \mathrm{w} \%)$
性が強いといわれていることや,7,8) 同定した脂肪酸以外 の物質がかなり含有されており，この物質の安全性ある いは有効性が明確にされていないことから，薬剤学的に はオレイン酸の単一成分である高純度品を用いる方が良 いと考光る.しかし従来はほとんど一級品を原料とした 製剤であるため, 硬化剤としての評価は今後の臨床にお ける成績が重要となろう。

次に Evans 社の EO- $i$ 中の OA のクロマトグラムを Fig. 1(c) 飞示す.これは Fig. 1(a) と同様のクロマト グラムであり, また EO- $i$ 中の OA のオレイン酸含量 が66\% (EO- $i$ 中の OA の含量を $4.23 \%$ とする) である ことから，JIS 一級品と同程度の品質と考えられる。こ のことは $\mathrm{OA}$ 飞関する $\mathrm{JIS}^{\left.{ }^{2}\right)}$ と $\mathrm{BP}^{1)}$ を比較すると, 両 方とるオレイン酸の含量の規定はなく, その他の項目は 同様であることからも明らかである.

2）分割使用時の安定性と保存法

$\mathrm{OA}$ 中の PO の含有量を測定したところ $\mathrm{A}^{\prime}$ のみ高い 值を示した (Table 3). $\mathrm{A}^{\prime}$ 以外は開封直後に測定した が, $\mathrm{A}^{\prime}$ は開封後 20 力月間に 9 回分割使用しており, 液 量は容器の $2 / 3$, 保存は室温暗所であった. PO の量が 增加した原因としてヘッドスペース，キャップ部からの 酸素の透過，および温度の影響が考えられる．そこで JIS 一級品には保存条件に温度の規定はないが，温度の
Table 3. Results of Quality Test for OA

\begin{tabular}{ccccc}
\hline Sample Appearance lodine value & \multicolumn{3}{c}{$\begin{array}{c}\text { Content Peroxide } \\
(\mathrm{w} / \mathrm{w} \%)\end{array}$} \\
& & & $\begin{array}{c}\text { (meq/kg) } \\
(\mathrm{m} / \mathrm{k}\end{array}$ \\
\hline A & Pale yellow & 92.3 & 69.9 & 1.5 \\
A' $^{\prime}$ & Pale yellow & 89.4 & 65.0 & 26.6 \\
B & Pale yellow & 85.9 & 65.8 & 2.6 \\
C & Pale yellow & 87.3 & 67.6 & 2.5 \\
D & Colorless & 90.0 & $100^{*}$ & 2.0 \\
\hline
\end{tabular}

* Used for standard

Table 4. Effect of Temperature on the Stability of OA

\begin{tabular}{cccc}
\hline Sample & Storage & $\begin{array}{c}\text { Storage time } \\
\text { (month) }\end{array}$ & $\begin{array}{c}\text { Peroxide } \\
\text { (meq/kg) }\end{array}$ \\
\hline \multirow{2}{*}{ B } & Room temp. & 1 & 12.1 \\
& Cold place & 2 & 4.3 \\
C & Room temp. & 1 & 18.1 \\
& Cold place & 2 & 7.8 \\
\hline
\end{tabular}

PO の生成への影響が大きいと考兄検討した (Table 4).. $\mathrm{B}, \mathrm{C}$ の原料はいずれも冷所 $\left(4 \sim 6^{\circ} \mathrm{C}\right)$ と室温の暗所に. 
Table 5. Physical Properties of EO- $i$

\begin{tabular}{cccc}
\hline \hline OA & pH & $\begin{array}{c}\text { Viscosity } \\
\text { (cP) }\end{array}$ & Color \\
\hline A & 9.0 & 3.1 & Pale yellow \\
D & 9.1 & 4.8 & Colorless \\
\hline
\end{tabular}

Table 6. Effect of Sterilization Time at $115^{\circ} \mathrm{C}$ on Peroxide of EO- $i$

\begin{tabular}{cccccc} 
& & \multicolumn{4}{c}{$(\mathrm{meq} / \ell)$} \\
\hline & \multicolumn{4}{c}{$\begin{array}{c}\text { Sterilization time } \\
(\mathrm{min})\end{array}$} \\
\cline { 2 - 6 } OA & 0 & 5 & 10 & 20 & 40 \\
\hline & 0 & 0.08 & 0.08 & 0.08 \\
A $^{\prime}$ & 1.00 & 0.08 & 0.08 & 0.04 & 0.06 \\
D & 0.08 & 0.08 & 0.08 & 0.04 & \\
\hline
\end{tabular}

Table 7. Effect of Light and Temperature on the Stability of $\mathrm{EO}-i$

\begin{tabular}{|c|c|c|c|c|c|}
\hline \multirow{3}{*}{ OA } & & & \multicolumn{3}{|c|}{$\begin{array}{l}\text { Peroxide } \\
(\text { meq } / \ell)\end{array}$} \\
\hline & \multicolumn{2}{|l|}{ Storage } & \multicolumn{3}{|c|}{$\begin{array}{c}\text { Time after preparation } \\
\text { (month) }\end{array}$} \\
\hline & Light & Temp. & 0 & 1 & 3 \\
\hline A & $\begin{array}{c}\text { Dark } \\
\text { Dark } \\
\text { Under lamp * }\end{array}$ & $\begin{array}{l}\text { Cold*2 } \\
\text { Room } \\
\text { Room }\end{array}$ & $\begin{array}{l}0.10 \\
0.10 \\
0.10\end{array}$ & $\begin{array}{l}0.08 \\
0.15 \\
0.24\end{array}$ & $\begin{array}{l}0.08 \\
0.11 \\
0.11\end{array}$ \\
\hline$D$ & $\begin{array}{c}\text { Dark } \\
\text { Dark } \\
\text { Under lamp *1 }\end{array}$ & $\begin{array}{l}\text { Cold*2 } \\
\text { Room } \\
\text { Room }\end{array}$ & $\begin{array}{l}0.02 \\
0.02 \\
0.02\end{array}$ & $\begin{array}{l}0.03 \\
0.03 \\
0.04\end{array}$ & $\begin{array}{l}0.01 \\
0.03 \\
0.08\end{array}$ \\
\hline
\end{tabular}

*1 Under fluorescent lamp (1000 lux) *2 $4 \sim 6^{\circ} \mathrm{C}$

保存し，液量は $500 \mathrm{ml}$ ビンの $1 / 2$ とした。その結果両 者とも PO の量は室温 1 カ月後で高い値を示した。また ヨウ素価, 含量にはほとんど変化はなかった. JIS 一級 品は $500 \mathrm{ml}$ 包装であり, 通常は分割使用するため冷暗所 水保存し、ヘッドスペースや使用期限を考慮して取扱う 必要がある。な拉, 高純度品のDは褐色のアンプル容器 で, 黒色紙で外装してあり保存温度は $2 \sim 10^{\circ} \mathrm{C}$ と明記さ れている。また 1 アンプル10g と少容量で分割使用しな いため, 安定性の検討は行わなかった.

\section{2. オレイン酸原料と EO-i の関係}

1) EO- $i$ の理化学的特性

$\mathrm{JIS}$ 一級品と高純度品を用いたときの EO- $i$ の理化学 的特性の比較を行った (Table 5). $\mathrm{pH}$ はほとんぞ同じ であるが粘度は高純度品の方が高い．乙かしこの程度の 粘度の差は硬化療法の手技にほとんど影響を与兄なかっ た. 色は JIS 一級品では隇菌 $\left(115^{\circ} \mathrm{C}, 30\right.$ 分) 後に淡黄 色が濃くなり变化がみられたが, 高純度品では滅菌前後 とも無色であった。

2) $E O-i$ 中の過酸化物の変化

Table 6 K EO- $i$ の滅菌時間と PO の含有量の関係
を示した。なお PO の規格範囲として, 新井ら ${ }^{9)}$ が静注 用脂肪乳剂中の $P O$ の規格範囲とした $0.5 \mathrm{mEq} / 1$ 以下 を採用した．滅菌前では OA 間で PO の含有量に差が あっても5 分以降では両方とも低い值となった.すなわ ち, 自動酸化の初期生成物質である $\mathrm{PO} か ゙ ~ 115^{\circ} \mathrm{C}$ の温 度条件で, 速やかに他の分解物に变化し, PO の含有量 が減少していったと思われる。したがって隇菌直後では 使用する OA 中の PO の含有量にかかわらず EO- $i$ 中 のPO はほとんど存在しなくなることから，POによる $\mathrm{EO}-i$ の品質試験を行ら際には原料中の PO に関する試 験が重要である.なお 40 分後においてす $\mathrm{pH}$ ，オレイン 酸含量変化はみられなかった。

次に EO- $i$ の安定性に及ぼす温度, 光の影響を検討し た (Table 7). その結果 JIS一級品, 高純度品とも 3 力 月間で温度, 光によるPO の生成量は低い值であった. また武田ら ${ }^{6)}$ の報告と同様に 3 力月後で含量, $\mathrm{pH}$ の変 動はほとんどみられなかった。

結論

1. JIS 一級品のオレイン酸含量は $65 〜 70 \%$ と低く， 
混在物の多いことが判明した。また混在物中に飽和脂肪 酸が約10\%含まれていた。

2. JIS 一級品を室温暗所保存した場合, 冷暗所保存 飞比してPO の含有量が増大したため, JIS 一級品を分 割使用する場合には温度, 空気の影響を考虑して保存し なければならない。

3. JIS 一級品と高純度品を用いた場合の EO- $i$ を比 較すると, $\mathrm{pH}$ ほ注ぼ同じであるが粘度，色湋いがみ られた。

4. $\mathrm{EO}-i$ の滅菌直後では $\mathrm{OA}$ 中の $\mathrm{PO}$ の含有量の多 少にかかわらず，PO の含有量は少なかった。また， $\mathrm{EO}-i$ の温度, 光による $\mathrm{PO}$ の生成, オレイン酸含量, $\mathrm{pH}$ への影響は 3 カ月間で JIS 一級品, 高純度品どちら の場合でもみられなかった。

5. 食道静脈瘤の硬化剂として JIS 一級品之高純度品 のどちらが有用かつ安全かの臨床評価は今後の課題であ るか゚, 薬剤学的な面からは高純度品の使用が望ましいと
考える.

$$
\text { 文献 }
$$

1) British Pharmacopoeia, 1980.

2) C.C.M. Watson : Br. Med. J., 1, 1481 (1958).

3) A.W.Clark, B.R.D. Macdougall, D. Westaby : Lancet, 2, 552 (1980).

4) 高瀬靖広, 中原朗 : Progress of Digestive Endoscopy, 13, 34 (1978).

5）武田光志, 須賀肇, 家田重義, 吉野清高, 町島 啓, 高瀬靖広, 岩崎洋治: 病院薬学, 10, 35 (1984).

6）武内次夫, 大野武男監修 : “試薬・工薬 JIS要覧,” 新日本法規出版, 1977.

7) W.E. Connor, J.C. Hoak, E.D. Warner : J. Clin. Invest., 42, 860 (1963).

8) 松田裕子, 金井弘一: 消化器科, 1, 58 (1984).

9) 新井克明, 堀内学, 荻野雅資, 佐藤信一, 吉野清 高, 町島啓: 病院薬学, 10,431 (1984).

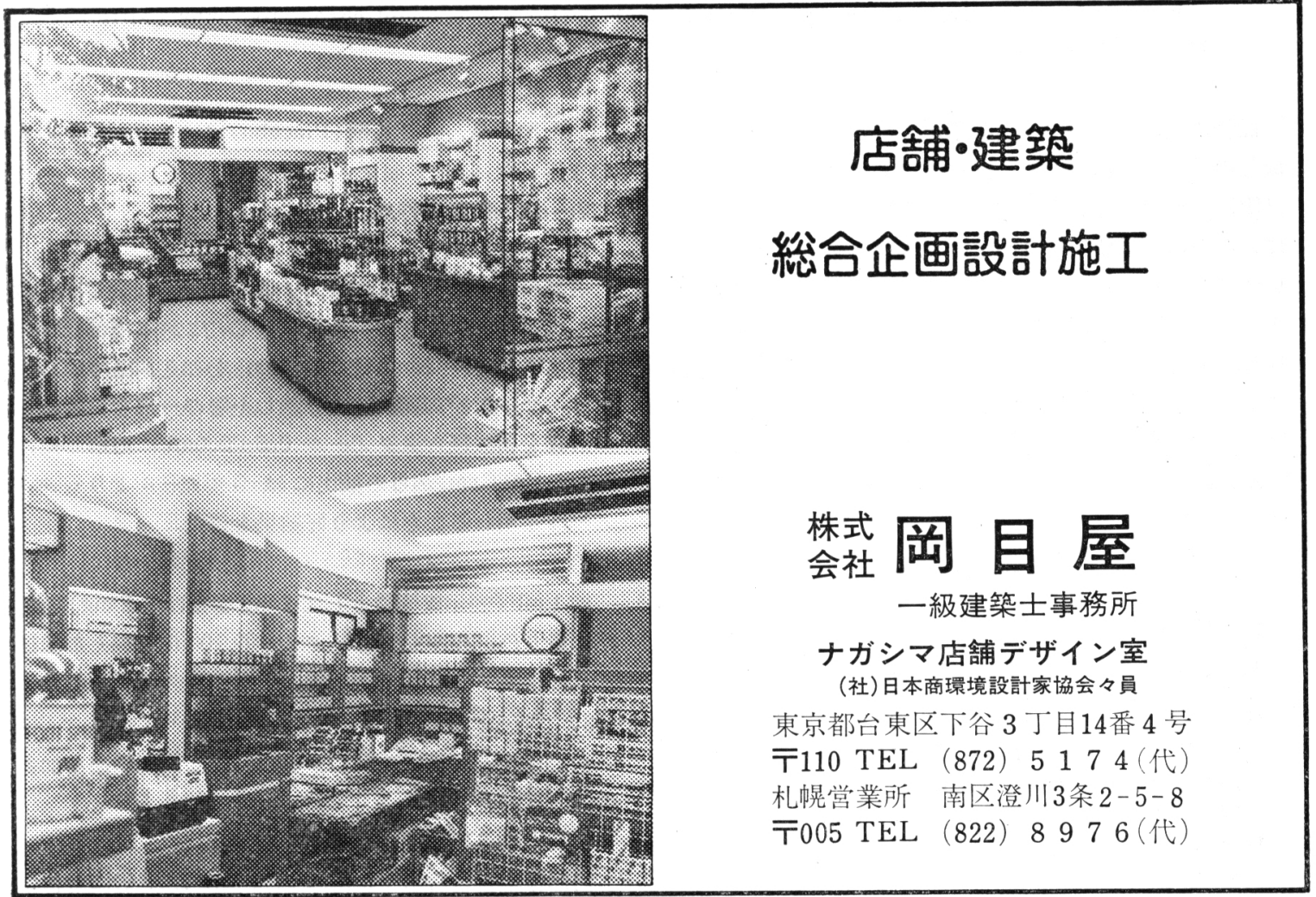

